\title{
The Psychosocial Effects of Taekwondo Training: A Meta-Analysis
}

\author{
Yu-Jin Kim ${ }^{1}$, Seung-Hui Baek ${ }^{2} \mathbb{D}$, Jong-Beom Park ${ }^{3}$, Sang-Hwan Choi ${ }^{3}$, Jae-Don Lee ${ }^{3}$ and Sang-Seok Nam ${ }^{3, * \mathbb{C}}$ \\ 1 Department of Physical Education, Sejong University, Seoul 05006, Korea; uzkimsp@gmail.com \\ 2 Department of Health Exercise Management, Sungshin Women's University, Seoul 02844, Korea; \\ sh100@sungshin.ac.kr \\ 3 Taekwondo Research Institute of Kukkiwon, Seoul 06130, Korea; jb1907@hanmail.net (J.-B.P.); \\ cshtkd@hanmail.net (S.-H.C.); drlee@kukkiwon.or.kr (J.-D.L.) \\ * Correspondence: playdata.n@gmail.com
}

check for updates

Citation: Kim, Y.-J.; Baek, S.-H.; Park, J.-B.; Choi, S.-H.; Lee, J.-D.; Nam, S.-S The Psychosocial Effects of Taekwondo Training: A Meta-Analysis. Int. J. Environ. Res. Public Health 2021, 18, 11427. https:// doi.org/10.3390/ijerph182111427

Academic Editor: Britton W. Brewer

Received: 13 September 2021

Accepted: 27 October 2021

Published: 30 October 2021

Publisher's Note: MDPI stays neutral with regard to jurisdictional claims in published maps and institutional affiliations.

Copyright: (c) 2021 by the authors. Licensee MDPI, Basel, Switzerland. This article is an open access article distributed under the terms and conditions of the Creative Commons Attribution (CC BY) license (https:// creativecommons.org/licenses/by/ $4.0 /)$.

\begin{abstract}
Taekwondo is a Korean martial art and international sport, and its psychosocial benefits for its trainees have been studied extensively. This review aims to systematically assess and meta-analyze the effects of Taekwondo training on sociality, character, etiquette, and school life adjustment. We searched the RISS, NDSL, and KISS electronic databases between January 1985 and December 2019. We also included gray literature, such as theses, in addition to peer-reviewed articles. R software (version 3.6.2, R Core Team, Vienna, Austria) was used to synthesize the effect sizes and perform moderation analyses. Twenty-eight studies ( 24 cross-sectional and four intervention studies) were included in the final meta-analysis. Significant positive effects of Taekwondo training were found on sociality ( $\mathrm{MD}=0.266,95 \% \mathrm{CI}: 0.191$ to 0.341 ), character (MD $=0.446,95 \% \mathrm{CI}: 0.331-0.560$ ), etiquette $(\mathrm{MD}=0.562,95 \% \mathrm{CI}: 0.500-0.624)$, and school life adjustment $(\mathrm{MD}=0.308,95 \% \mathrm{CI}: 0.195-0.421)$. Overall, the findings of this meta-analysis support that Taekwondo can have a positive impact on the psychosocial factors of trainees. Due to several limitations discussed, well-designed RCTs and multiple levels of Taekwondo intervention studies should be conducted in future research to validate the current findings.
\end{abstract}

Keywords: taekwondo; sociality; character; etiquette; school life adjustment; meta-analysis

\section{Introduction}

Taekwondo is an internationally established martial art, included in the Olympic Games, and is practiced today by millions of people in more than 200 countries (International Olympic Committee, 2021). Despite some controversies regarding its origin and history, Taekwondo is known to have evolved from a form of unarmed military training of ancient kingdoms of the Korean peninsula, including Hwarang, an elite scholar-warrior group of male youth in the Silla kingdom [1]. Though it originated from a fighting system for self-defense, Taekwondo is enjoyed as a sport effective for health promotion and self-discipline, regardless of age and gender. In addition to the physical and psychological benefits of training in a sport, it has also been widely practiced as a vehicle for developing practitioners' mental strength and ethics [2]. Distinctively, Taekwondo places a significant value in positively affecting practitioners' behavior and spirit through the training process [3].

The name Taekwondo is derived from the Korean words "tae", meaning feet or kick, "kwon", meaning fist or punch, and "do", meaning path or realization. As its name represents, the Taekwondo spirit can be described by the concept of "do." This meditative aspect of the forms in Taekwondo includes learning Taekwondo etiquette and the training of minds, encouraging practitioners to achieve self-realization through advancement of both body and mind, and to apply it in their lives [4]. To shape "do," Taekwondo philosophy teaches five core tenets: courtesy, integrity, perseverance, self-control, and indomitable 
spirit $[5,6]$. Historically, these lessons have been associated with pursuing peace, having respect to one another, and standing in solidarity with individuals weaker in body, mind, and spirit [7]. These tenets are consistent with the principle that Taekwondo skills should be used only with good and peace as the ultimate goals.

One of the reasons behind Taekwondo's global expansion and popularity over the years may be its positive impact on multiple aspects of personality development such as values, beliefs, self-development, manners, leadership, social skills, and confidence [8]. For decades, studies have reported that it has beneficial effects on trainees' social development, especially children and adolescents, by improving personality, manners, and behavior, and contributes to adaptation to and satisfaction with school life [9-12].

In terms of personality development, Lim [13] reported that a 12-week Taekwondo intervention for elementary school 2nd-4th graders resulted in significant improvements in leadership, confidence, and manners. Similarly, preschoolers who participated in 15 sessions of a physical activity program using Taekwondo over eight weeks demonstrated higher scores on personality assessments in the lifestyle, self-establishment, sense of community, physical development, and sociality subscales compared with the controls [8].

Taekwondo training has long been reported to be effective in enhancing the social traits of practitioners $[3,14,15]$. Sociality, a distinct human trait that prompts the need to associate with social groups, is a fundamental characteristic of survival and coexistence with others. According to a study that investigated the correlation between self-regulation and sociality in elementary school students practicing Taekwondo, depending on the duration, the training period explained differences in diligence, interpersonal relationships, and responsibility, suggesting that regular Taekwondo training has a positive effect on social development [16]. They also found that self-regulation affected sociality factors such as diligence, responsibility, interpersonal relationships, and cooperation. Furthermore, in a recent study by Bae and Roh [17], who conducted a 16-week Taekwondo intervention designed for children from multicultural families, it was observed that overall sociability scores improved after the intervention, with reduced scores on feelings of isolation. These findings indicate that individuals learn perseverance and self-control in Taekwondo training, and internalization of these traits may contribute to social development and adaptation to the group.

Taekwondo has been well received by schools and parents who expected it would assist students in adapting to school life and in forming desirable etiquette and character during a critical period of development. Many of today's young students are forced to live a uniform and passive life within the framework set by adults, and experience social disconnection due to lack of family integrity, highly competitive education, and school violence, along with increased time spent in online activities [18]. In this context, Taekwondo has been discussed as a possibly effective option for many psychological and social problems, such as the school violence, bullying, and delinquency to which children and adolescents are exposed [19].

Previous studies have provided evidence that Taekwondo can be an effective tool for school life adjustment and the satisfaction of growing children by promoting selfregulation and social development. However, these studies vary in the assessment tools and the subfactors used in their investigations. Furthermore, differences in sample size, sample type, sex, age, and study design (i.e., intervention or cross-section) in past studies also limit the generalizability of the results. Therefore, a systematic integration of studies that have been published to date is required to verify the effects of Taekwondo training on the psychosocial characteristics of practitioners.

This research comprised a meta-analysis of the available literature to provide a systematic review of the effects of Taekwondo training on psychosocial factors including sociality, character, etiquette, and school life adjustment. 


\section{Materials and Methods}

\subsection{Study Selection}

This study was performed according to the Preferred Reporting Items for Systematic reviews and Meta-Analyses (PRISMA) statement in the Cochrane protocols [20]. We searched studies conducted between January 1985 and December 2019 using the Research Information Sharing Service (RISS), National Digital Science Library (NDSL), and Korean Studies Information Service System (KISS) electronic databases. The literature search formula was constructed using both Korean and English: (("sociality" OR "social development"[Title/Abstract])<AND $>$ ("taekwondo"[Title/Abstract])), (("character"[Title/Abstract]) <AND>("taekwondo"[Title/Abstract])), (("manner" OR "courtesy" OR "etiquette" [Title/Abstract]) $<$ AND $>$ ("taekwondo"[Title/Abstract])), and (("school life adjustment" [Title/Abstract]) $<$ AND $>$ ("taekwondo"[Title/Abstract])). The search strategy was adapted to each database.

The research papers were first screened according to the population, intervention, comparison, and outcome (PICO) criteria. The participants (P) of our review were limited to Taekwondo practitioners compared with non-practitioner controls. Since this study aimed to examine the effects of Taekwondo training on the general population, studies targeting Taekwondo athletes, demonstration members, Taekwondo majors, instructors, and referees were excluded. The intervention method (I) was a Taekwondo training program, including both intervention and cross-sectional studies. The comparative group (C) comprised those who did not participate in the Taekwondo training. The outcome (O) or dependent variables were sociality (subfactors: activity, autonomy, capability, cooperation, law-abidance, leadership, responsibility, sociability, and stability), character (subfactors: sense of community, confidence, consideration, emotionality, leadership, living, propriety, self-establishment, and self-esteem), etiquette (subfactors: deportment, greeting, interpersonal etiquette, language, listening, phone etiquette, etiquette in public places, dining etiquette, and visiting etiquette), and school life adjustment (subfactors: learning, school events, friendship, rule compliance, and teacher relations). We only included studies that presented the mean and standard deviation of the outcome measures. To reduce publication bias, gray literature, such as theses, was also included in addition to peer-reviewed literature published in academic journals. The languages of the literature were limited to Korean and English.

\subsection{Statistical Methods}

We examined the moderator effects of sample size, sex, age, study type, publication type, and quality of the study on outcome measures. Sex was classified into three categories according to the proportion of male participants. Studies where the proportion of males was $33 \%$ or less of the total participants were set as " 1 ," studies with less than $66 \%$ male participants were set as " 2, " and studies with $66 \%$ males or more were set as " 3 ." In terms of age, " 1 " indicated studies of elementary school students or younger, " 2 " for middle and high school students, and " 3 " for college students.

We used the Newcastle Ottawa Scale (NOS) recommended by the Cochrane Collaboration, to assess the risk of bias in case-control studies. The NOS contains eight items across the three domains. The selection domain includes four items: (1) adequacy of case definition, (2) representativeness of the cases, (3) selection of controls, and (4) definition of controls. The comparability domain contains one item: comparability of cases and controls on the basis of the design or analysis. The exposure domain has three items: (1) ascertainment of exposure, (2) same method of ascertainment for cases and controls, and (3) non-response rate. A star system was employed to assess the quality of the included studies, with the highest quality in each item receiving a maximum of one star, except for the item in the comparability domain, which allowed the assignment of two stars. The total quality scores evaluated using the NOS ranged from zero to nine stars.

The heterogeneity of the effect sizes was assessed using $R$ version 3.6.2 (The R Foundation, Vienna, Austria). Analysis of the overall effect size was performed when there were 
three or more identical outcome variables. Since the outcome measures were on five-point scales, all analysis results were presented with mean difference (MD) and 95\% confidence intervals $(\mathrm{Cl})$. A random-effects model was used under the assumption that the effects estimated in different studies were heterogeneous [21]. We performed meta-ANOVA and meta-regression analysis for each moderator variable and used a restricted maximum likelihood (REML) to estimate both continuous (e.g., sample size) and categorical variables (sex, age, research period, publication type). Heterogeneity was assessed using the Cochrane's $Q$ and Higgins $I^{2}$ statistics, with the $p$-value of the Cochrane's $Q$ test 0.1 or less or the Higgins $\mathrm{I}^{2} 50 \%$ or more judged as statistically significant heterogeneity. We presented publication bias with a contour funnel plot and performed a sensitivity analysis using trim-and-fill, if necessary.

\section{Results}

\subsection{Characteristics of Included Studies}

A total of 796 studies (RISS, $n=360$; NDSL, $n=363$; KISS, $n=73$ ) emerged as a result of the initial database search. Among the searched studies, 768 studies were excluded due to the following reasons: (a) overlapping $(n=389)$, (b) irrelevant to "sociality," "character," "etiquette," or "adjustment to school life" ( $n=256)$, (c) no comparison group $(n=102)$, (d) sample size error, (e) inaccurate data analysis $(n=4)$, plagiarism $(n=8)$, and lack of sub-variables $(n=5)$. After article screening, 28 studies fulfilled the inclusion criteria and were included in the final analysis. The PRISMA flow chart of the article screening process is shown in Figure 1. Two independent researchers evaluated the risk of bias according to the NOS criteria of the Cochrane Collaboration. According to the quality evaluation results, 15 of the selected studies had good quality, seven were fair, and six had poor quality. The characteristics of each study are presented in Table 1.
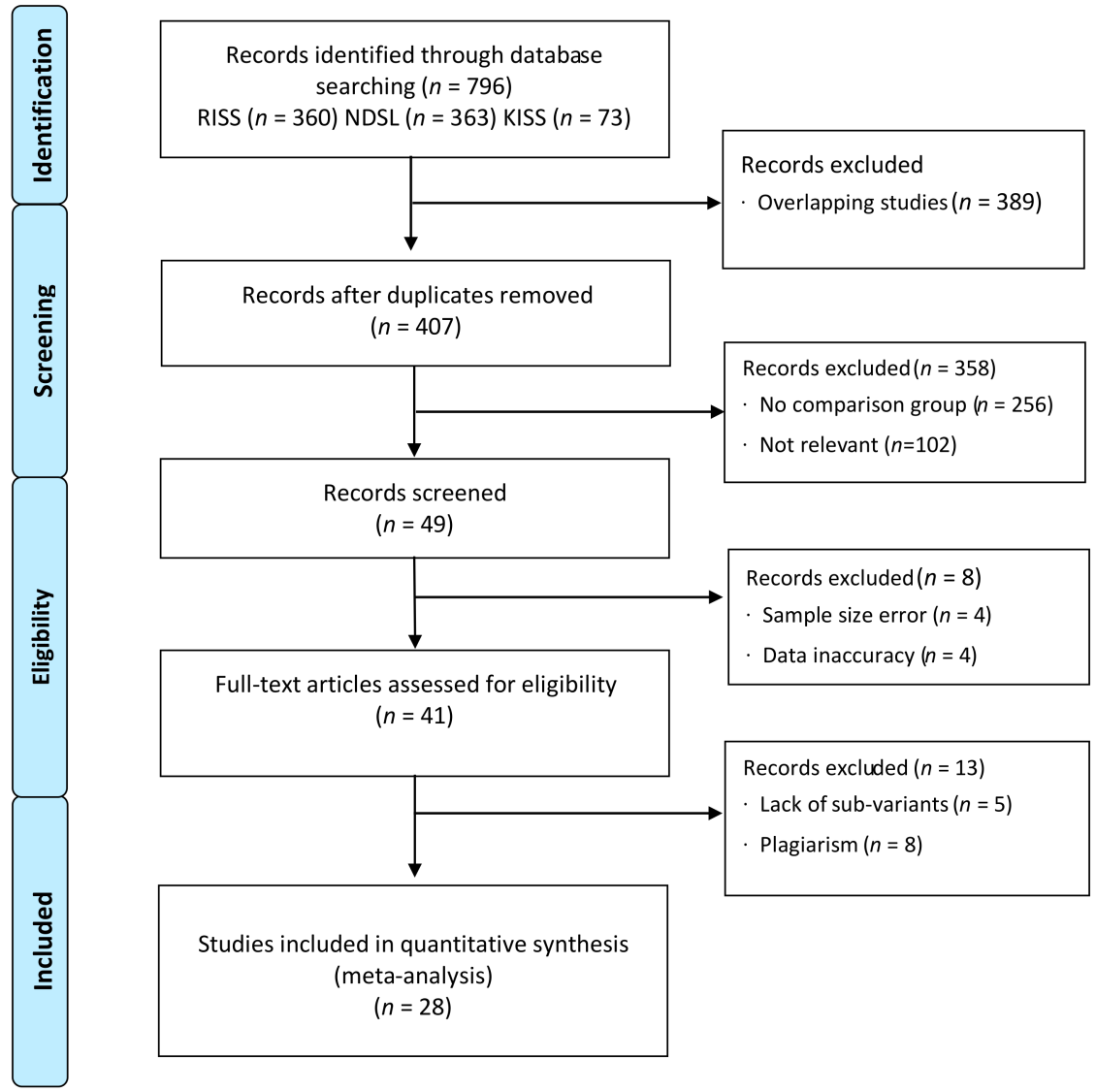

Figure 1. Flow chart of article screening process. 
Table 1. Characteristics of included studies.

\begin{tabular}{|c|c|c|c|c|c|}
\hline \multicolumn{6}{|c|}{ 1. Sociality } \\
\hline Author, Year & $\begin{array}{l}\text { No. Participants } \\
\text { (TKD, Control) }\end{array}$ & $\%$ Male & Age Group & Covariates & $\begin{array}{c}\text { Study Type } \\
\text { (Quality Score) }\end{array}$ \\
\hline Kang, 2010 [22] & $484(310,174)$ & $64.26 \%$ & elementary school & sex, grade, period, time, frequency & cross-section (9) \\
\hline Kim, 2006 [23] & $200(100,100)$ & $50.00 \%$ & high school & $\begin{array}{l}\text { sex, parent's education, standard of } \\
\text { living, health, period }\end{array}$ & cross-section (9) \\
\hline Kim, 2007 [24] & $330(228,102)$ & $61.21 \%$ & elementary school & sex, age, period & cross-section (9) \\
\hline Nam, 2005 [25] & $400(200,200)$ & $75.00 \%$ & elementary school & $\begin{array}{l}\text { parent's education, standard of } \\
\text { living, period }\end{array}$ & cross-section (9) \\
\hline An, 1997 [26] & $501(301,200)$ & $58.00 \%$ & elementary school & $\begin{array}{l}\text { sex, grade, parent's education, } \\
\text { period }\end{array}$ & cross-section (9) \\
\hline Yoon, 2005 [27] & $493(266,227)$ & $71.40 \%$ & elementary school & sex, grade, & cross-section (9) \\
\hline Lee, 2008 [28] & $675(354,321)$ & unknown & high school & $\begin{array}{l}\text { grade, academic achievement, } \\
\text { period, frequency, time }\end{array}$ & cross-section (7) \\
\hline Lim,2009 [3] & $70(30,40)$ & unknown & elementary school & unknown & $\begin{array}{l}\text { Intervention (8) } \\
\text { 24-week }\end{array}$ \\
\hline \multicolumn{6}{|c|}{ 2. Character } \\
\hline Author, Year & $\begin{array}{l}\text { No. Participants } \\
\text { (TKD, Control) }\end{array}$ & $\%$ Male & Age Group & Covariates & $\begin{array}{l}\text { Study Type (Quality } \\
\text { Score) }\end{array}$ \\
\hline Choi, 2015 [10] & $40(20,20)$ & $14.48 \%$ & preschool & - & $\begin{array}{l}\text { Intervention (9) } \\
\text { 8-week }\end{array}$ \\
\hline Han, 2005 [29] & $200(100,100)$ & $50 \%$ & elementary school & sex, grade & cross-section (9) \\
\hline Hong, $2010[30]$ & $449(299,150)$ & $48.55 \%$ & elementary school & $\begin{array}{l}\text { sex, grade, period, time } \\
\text { sex, grade, parent's job, career, }\end{array}$ & cross-section (9) \\
\hline Jung, 2007 [31] & $200(100,100)$ & $50 \%$ & elementary school & $\begin{array}{l}\text { period, frequency, a single-parent } \\
\text { family, number of siblings }\end{array}$ & cross-section (9) \\
\hline Lee,2005 [32] & $642(399,342)$ & $53.20 \%$ & elementary school & $\begin{array}{l}\text { sex, grade, training place, period, } \\
\text { frequency, time }\end{array}$ & cross-section (7) \\
\hline Lim, 2008 [33] & $342(171,171)$ & $65.50 \%$ & elementary school & $\begin{array}{l}\text { sex, grade, academic achievement, } \\
\text { career, tutoring, standard of living }\end{array}$ & cross-section (8) \\
\hline Lim, 2015 [13] & $55(28,27)$ & unknown & elementary school & - & $\begin{array}{l}\text { intervention (9) } \\
\text { 12-week }\end{array}$ \\
\hline You, 2012 [34] & $200(100,100)$ & $0 \%$ & college & grade, frequency & cross-section (7) \\
\hline Yoon, 2019 [35] & $59(41,18)$ & $6.78 \%$ & high school & Sex, grade, certification & $\begin{array}{l}\text { intervention (9) } \\
\text { 9-month }\end{array}$ \\
\hline \multicolumn{6}{|c|}{ 3. Etiquette } \\
\hline Author, Year & $\begin{array}{l}\text { No. Participants } \\
\text { (TKD, Control) }\end{array}$ & $\%$ Male & Age Group & Covariates & $\begin{array}{l}\text { Study Type (Quality } \\
\text { Score) }\end{array}$ \\
\hline Kim, 2006 [23] & $200(100,100)$ & $50.00 \%$ & high school & $\begin{array}{l}\text { sex, parent's education, standard of } \\
\text { living, health, period }\end{array}$ & cross-section (9) \\
\hline Lee, 2003 [36] & $338(228,110)$ & $74.56 \%$ & elementary school & sex, grade, parent's education & cross-section (9) \\
\hline Lee, 2008 [28] & $675(354,321)$ & unknown & high school & $\begin{array}{l}\text { grade, academic achievement, } \\
\text { period, frequency, time }\end{array}$ & cross-section (7) \\
\hline Yang, 2006 [37] & $566(294,272)$ & $59.36 \%$ & elementary school & $\begin{array}{l}\text { sex, age, standard of living, religion, } \\
\text { parent's education }\end{array}$ & cross-section (7) \\
\hline Hong, $2010[30]$ & $449(299,150)$ & $48.55 \%$ & elementary school & sex, grade, period, time & cross-section (9) \\
\hline Lim, 2017 [38] & $60(26,34)$ & unknown & elementary school & - & \\
\hline You, 2012 [34] & $200(100,100)$ & $0 \%$ & college & grade, frequency & cross-section (7) \\
\hline \multicolumn{6}{|c|}{ 4. School Life Adjustment } \\
\hline Author, Year & $\begin{array}{l}\text { No. Participants } \\
\text { (TKD, Control) }\end{array}$ & $\%$ Male & Age Group & Covariates & $\begin{array}{l}\text { Study Type (Quality } \\
\text { Score) }\end{array}$ \\
\hline Choi, 2008 [9] & $407(283,124)$ & $65.60 \%$ & elementary school & $\begin{array}{l}\text { sex, age, parent's education, period, } \\
\text { career }\end{array}$ & cross-section (9) \\
\hline Kim, 2007 [39] & $552(310,242)$ & $62.86 \%$ & elementary school & sex, grade & cross-section (7) \\
\hline Kim, $2011[40]$ & $299(156,143)$ & $100 \%$ & $\begin{array}{l}\text { elementary, middle } \\
\text { school }\end{array}$ & grade & cross-section (8) \\
\hline Kim, 2015 [41] & $281(193,88)$ & $56.94 \%$ & elementary school & sex, grade & cross-section (8) \\
\hline Kim, 2016 [42] & $389(216,173)$ & $46.79 \%$ & middle school & $\begin{array}{l}\text { sex, grade, residence, academic } \\
\text { achievement }\end{array}$ & cross-section (8) \\
\hline Yoo, 2013 [43] & $145(68,77)$ & $51.72 \%$ & elementary school & sex, grade & cross-section (5) \\
\hline Yoon, 2005 [44] & $360(240,120)$ & $60.12 \%$ & elementary school & $\begin{array}{l}\text { sex, age, standard of living, religion, } \\
\text { parent's education }\end{array}$ & cross-section (9) \\
\hline
\end{tabular}




\subsection{Outcome Measures}

\subsubsection{Sociality}

Pooling data from eight studies showed a significant positive effect of Taekwondo training on sociality $(\mathrm{MD}=0.266 ; 95 \% \mathrm{CI}, 0.191-0.341)$. There was high heterogeneity among the studies $\left(p<0.01, \mathrm{I}^{2}=91 \%\right)$. The differences between the subfactors were not statistically significant $(p=0.96)$. The overall effect size depending on the subfactors of sociality (leadership, sociability, stability, capability, autonomy, law-abidance, responsibility, cooperation, and activity) is presented in Figure 2.

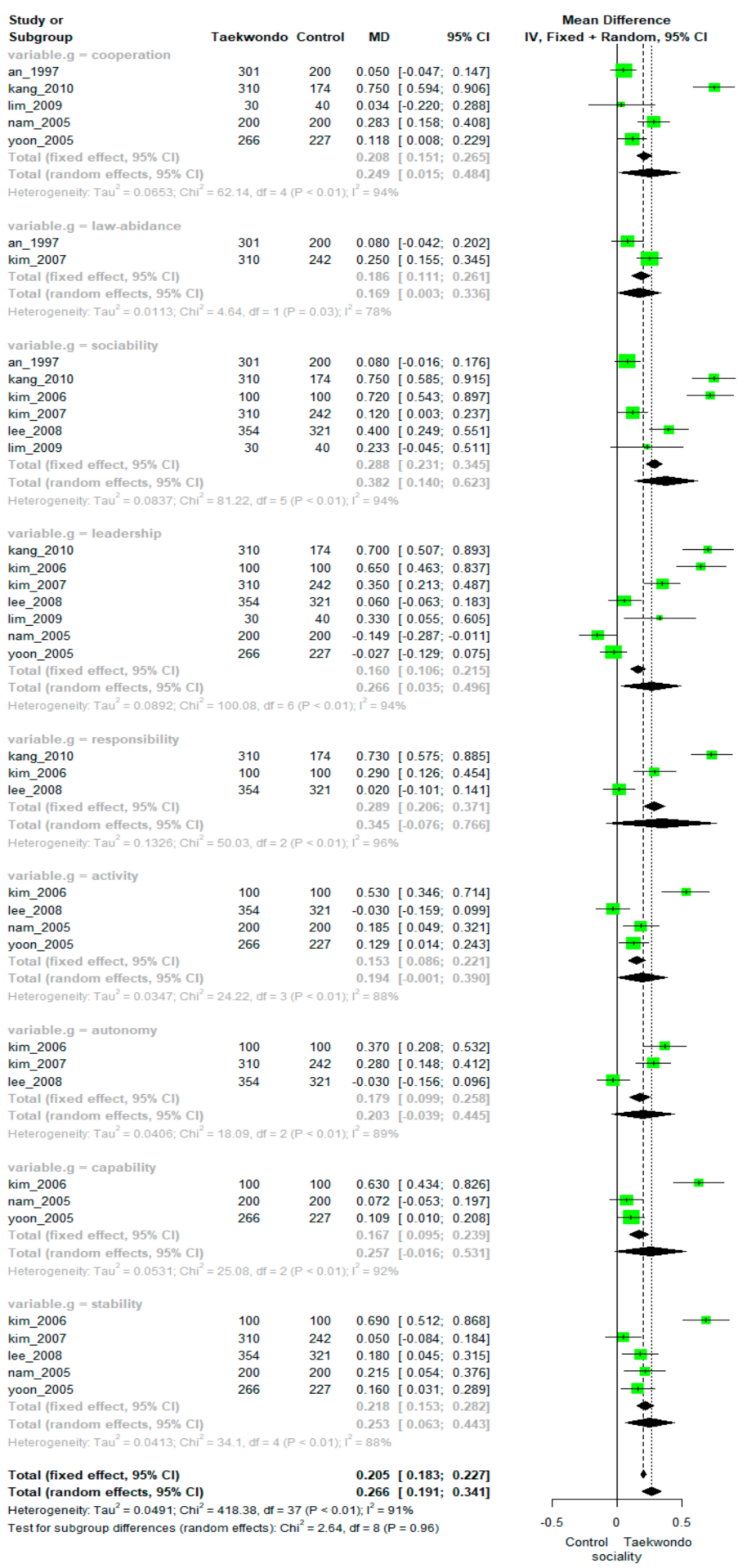

Figure 2. Forest plot of Taekwondo effects on sociality. 
Specifically, meta-analyses found significant positive effects of Taekwondo training on sociality in the following subfactors: cooperation ( $\mathrm{MD}=0.249,95 \% \mathrm{CI}: 0.015$ to 0.484 ; heterogeneity: $\mathrm{I}^{2}=94 \%, p<0.01$ ), law compliance (MD $=0.169,78 \% \mathrm{CI}: 0.060$ to 0.403 ; heterogeneity: $\mathrm{I}^{2}=78 \%, p=0.03$ ), leadership ( $\mathrm{MD}=0.266,95 \% \mathrm{CI}$ : 0.035 to 0.496 ; heterogeneity: $\left.\mathrm{I}^{2}=94 \%, p<0.01\right)$, responsibility (MD $=0.345,95 \% \mathrm{CI}:-0.076$ to 0.766 ; heterogeneity: $\mathrm{I}^{2}=96 \%, p<0.01$ ), sociability (MD $=0.382,95 \%$ CI: 0.140 to 0.623 ; heterogeneity: $\mathrm{I}^{2}=94 \%$, $p<0.01$ ), and stability ( $\mathrm{MD}=0.253,95 \%$ CI: 0.063 to 0.443 ; heterogeneity: $\mathrm{I}^{2}=88 \%, p<0.01$ ).

However, there were no significant differences between the Taekwondo training groups and controls in the following subfactors of sociality: activity (MD $=0.194,95 \% \mathrm{CI}$ : -0.001 to 0.390 ; heterogeneity: $\mathrm{I}^{2}=88 \%, p<0.01$ ), autonomy (MD $=0.203,95 \%$ CI: -0.039 to 0.445 ; heterogeneity: $\mathrm{I}^{2}=89 \%, p<0.01$ ), and capability (MD $=0.257,95 \% \mathrm{CI}:-0.016$ to 0.531 ; heterogeneity: $\mathrm{I}^{2}=92 \%, p<0.01$ ).

\subsubsection{Character}

Pooling data from nine studies showed a significant positive effect of Taekwondo training on character ( $\mathrm{MD}=0.446,95 \% \mathrm{CI}$ : 0.331 to 0.560 ). There was high heterogeneity among the studies $\left(p<0.01, \mathrm{I}^{2}=93 \%\right)$. The differences between the subfactors were not statistically significant $(p=0.84)$. The overall effect size depending on the subfactors of character (sense of community, confidence, consideration, emotionality, leadership, living, propriety, self-establishment, and self-esteem) is presented in Figure 3.

Specifically, meta-analyses found significant positive effects of Taekwondo training on character in the following subfactors: sense of community (MD $=0.520,95 \%$ CI: 0.190 to 0.850 ; heterogeneity: $\mathrm{I}^{2}=95 \%, p<0.01$ ), consideration (MD $=0.544,95 \%$ CI: 0.344 to 0.744 ; heterogeneity: $\mathrm{I}^{2}=62 \%, p=0.07$ ), emotionality (MD $=0.506,95 \%$ CI: 0.201 to 0.810 ; heterogeneity: $\mathrm{I}^{2}=91 \%, p<0.01$ ), leadership (MD $=0.393,95 \% \mathrm{CI}: 0.130$ to 0.656 ; heterogeneity: $\mathrm{I}^{2}=72 \%, p=0.03$ ), propriety ( $\mathrm{MD}=0.316,95 \% \mathrm{CI}: 0.047$ to 0.585 ; heterogeneity: $\mathrm{I}^{2}=84 \%, p<0.01$ ), living ( $\mathrm{MD}=0.402,95 \%$ CI: 0.083 to 0.721 ; heterogeneity: $\mathrm{I}^{2}=95 \%, p<0.01$ ), self-establishment (MD $=0.512,95 \% \mathrm{CI}$ : 0.184 to 0.840 ; heterogeneity: $\left.\mathrm{I}^{2}=95 \%, p<0.01\right)$, and self-esteem (MD $=0.561,95 \%$ CI: 0.118 to 1.005 ; heterogeneity: $\left.\mathrm{I}^{2}=96 \%, p<0.01\right)$.

However, there was no significant difference between the Taekwondo training groups and controls in the confidence subfactor (MD $=0.324,95 \% \mathrm{CI}$ : -0.150 to $0.792, p<0.01$; heterogeneity: $\mathrm{I}^{2}=93 \%$ ).

\subsubsection{Etiquette}

Pooling data from seven studies showed a significant positive effect of Taekwondo training on etiquette ( $\mathrm{MD}=0.562,95 \% \mathrm{CI}$ : 0.500-0.624). There was high heterogeneity among the studies $\left(p<0.01, \mathrm{I}^{2}=77 \%\right)$. The differences between the subfactors were not statistically significant $(p=0.28)$. The overall effect size depending on the subfactors of etiquette (deportment, greeting, interpersonal etiquette, language, listening, phone etiquette, etiquette in public places, dining etiquette, and visiting etiquette) is presented in Figure 4.

Specifically, meta-analyses found significant positive effect of Taekwondo training on etiquette in all the subfactors: deportment ( $\mathrm{MD}=0.384,95 \% \mathrm{CI}$ : 0.193 to 0.575 ; heterogeneity: $\mathrm{I}^{2}=83 \%, p<0.01$ ), greeting ( $\mathrm{MD}=0.590,95 \% \mathrm{CI}$ : 0.416 to 0.764 ; heterogeneity: $\left.\mathrm{I}^{2}=85 \% p<0.01\right)$, interpersonal etiquette $(\mathrm{MD}=0.577,95 \% \mathrm{CI}: 0.296$ to 0.856 ; heterogeneity: $\mathrm{I}^{2}=77 \% p=0.01$ ), language (MD $=0.633,95 \%$ CI: 0.524 to 0.743 ; heterogeneity: $\mathrm{I}^{2}=53 \%$, $p=0.06$ ), listening ( $\mathrm{MD}=0.699,95 \% \mathrm{CI}$ : 0.543 to 0.855 ; heterogeneity: $\mathrm{I}^{2}=42 \%, p=0.18$ ), phone etiquette ( $\mathrm{MD}=0.511,95 \%$ CI: 0.420 to 0.602 ; heterogeneity: $\mathrm{I}^{2}=0 \%, p=0.99$ ), etiquette in public places (MD $=0.551,95 \%$ CI: 0.380 to 0.721 ; heterogeneity: $\mathrm{I}^{2}=48 \%$, $p=0.15$ ), dining etiquette ( $\mathrm{MD}=0.601,95 \% \mathrm{CI}: 0.261$ to 0.940 ; heterogeneity: $\mathrm{I}^{2}=85 \%$, $p<0.01$ ), and visiting etiquette ( $\mathrm{MD}=0.518,95 \% \mathrm{CI}: 0.392$ to 0.644 ; heterogeneity: $\mathrm{I}^{2}=61 \%$, $p=0.05$. 


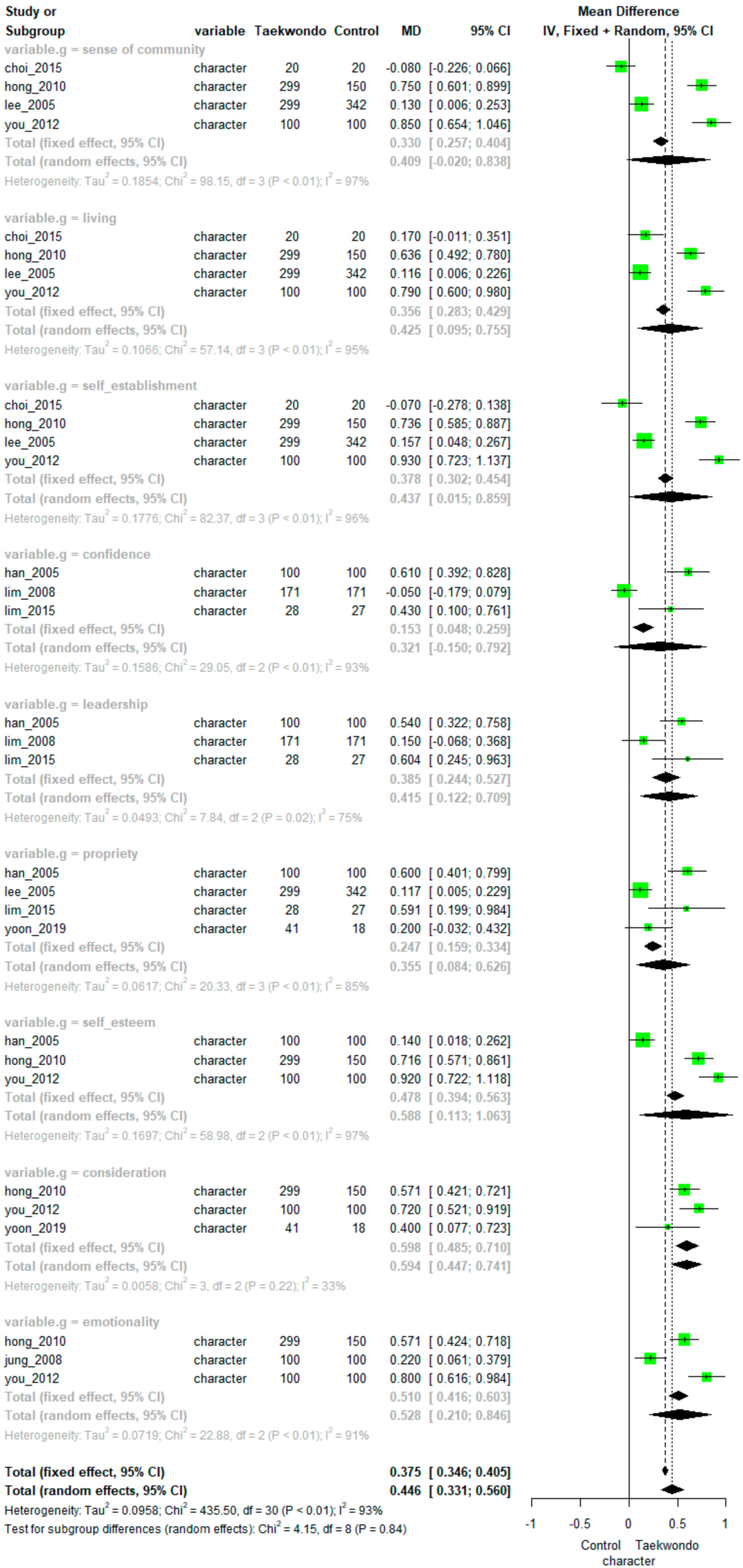

Figure 3. Forest plot of Taekwondo effects on character. 


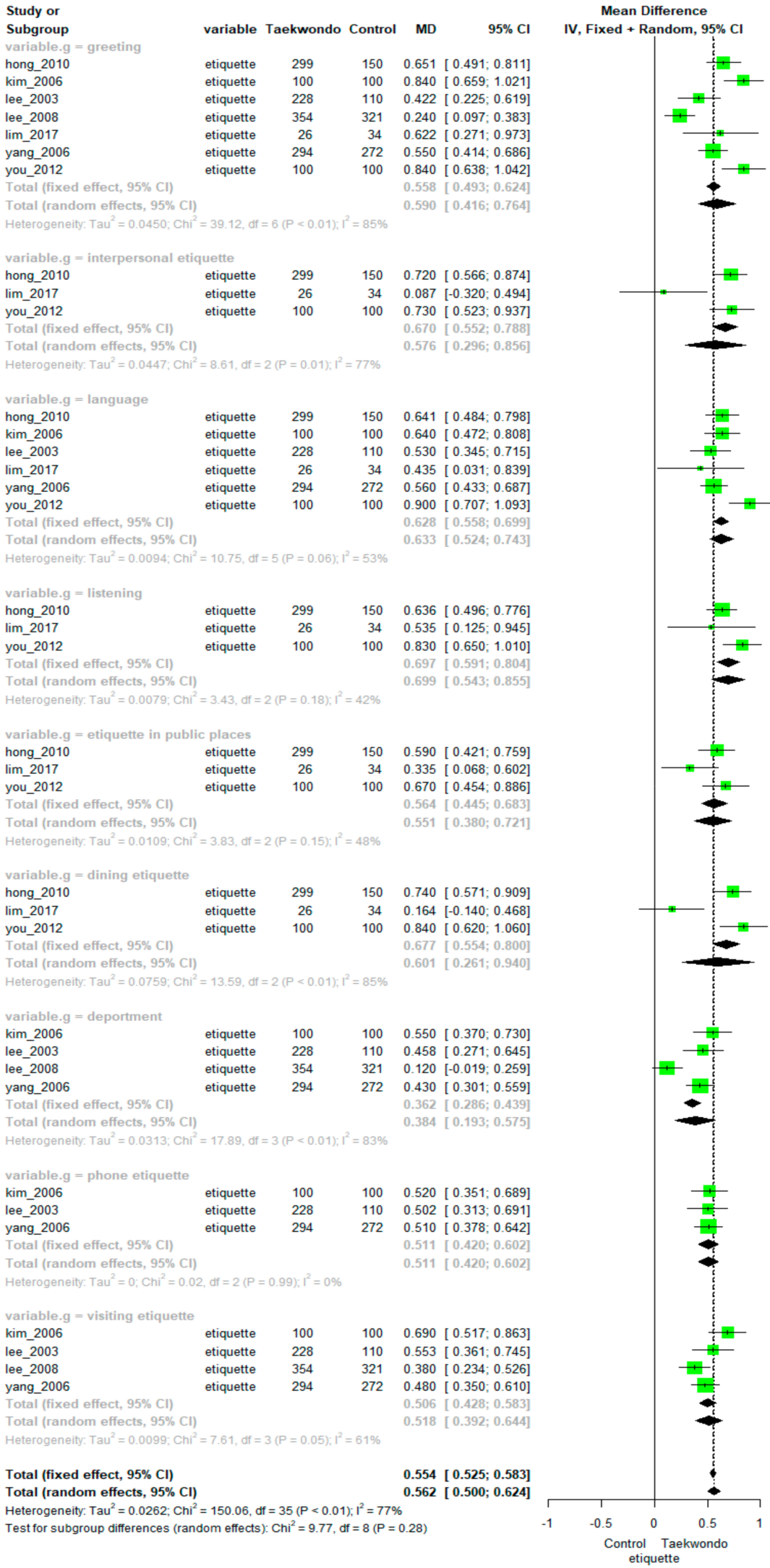

Figure 4. Forest plot of Taekwondo's effects on etiquette. 


\subsubsection{School Life Adjustment}

Pooling data from seven studies showed a significant positive effect of Taekwondo training on school life adjustment ( $\mathrm{MD}=0.308,95 \%$ CI: 0.195 to 0.421$)$. There was high heterogeneity among the studies $\left(p<0.01, \mathrm{I}^{2}=94 \%\right)$. The differences between the subfactors were not statistically significant $(p=0.53)$. The overall effect size depending on the subfactors of school life adjustment (learning, school events, friendship, rule compliance, and teacher relations) is presented in Figure 5.

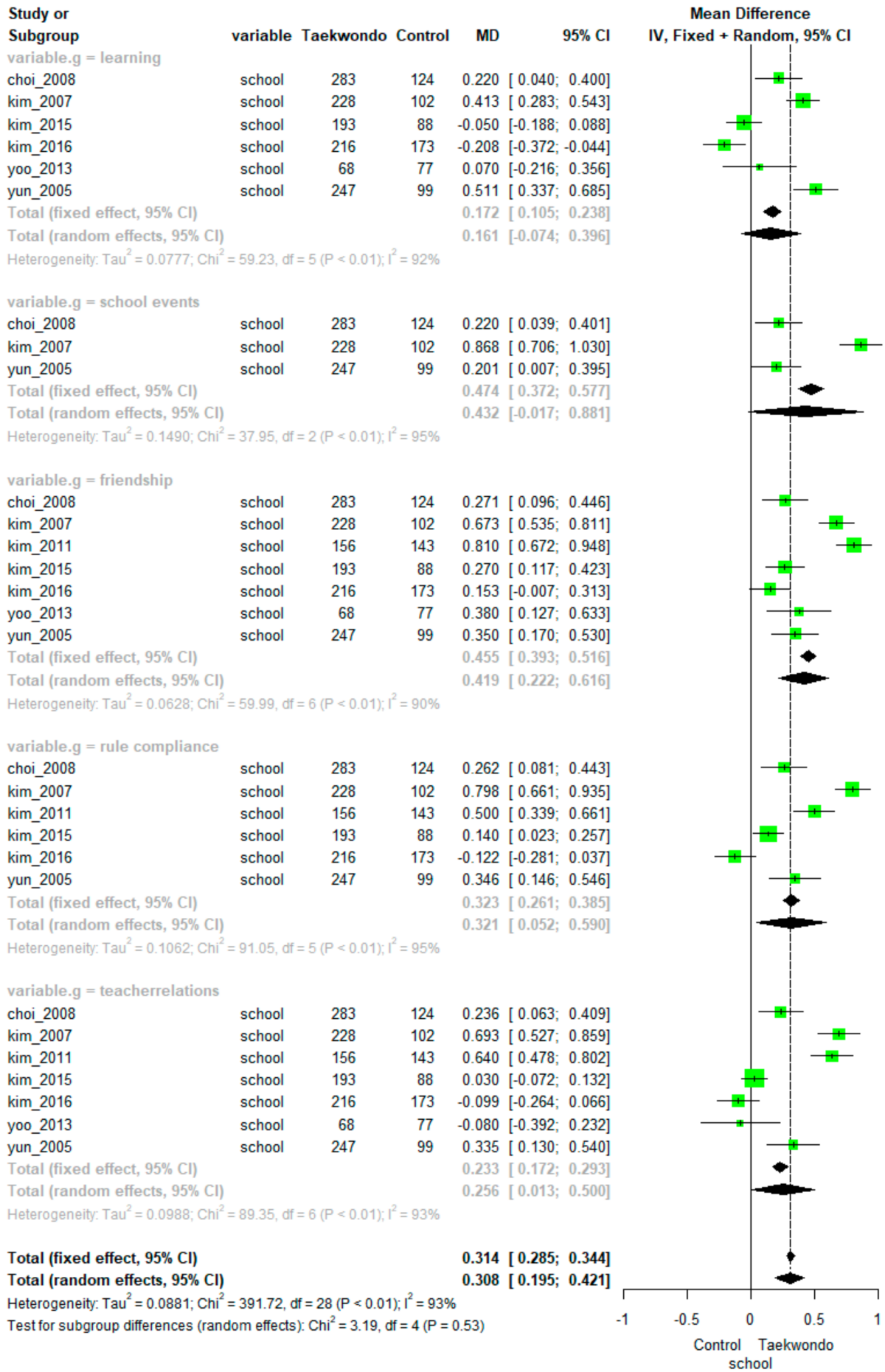

Figure 5. Forest plot of Taekwondo effects on school life adjustment. 
Meta-analyses found a significant positive effect of Taekwondo training on school life adjustment in the subfactors of learning (MD $=0.161,95 \% \mathrm{CI}$ : -0.074 to 0.396 ; heterogeneity: $\mathrm{I}^{2}=92 \%, p<0.01$ ), friendship (MD $=0.419,95 \% \mathrm{CI}: 0.222$ to 0.616 ; heterogeneity: $\mathrm{I}^{2}=90 \%$, $p<0.01$ ), rule compliance $\left(\mathrm{MD}=0.321,95 \% \mathrm{CI}: 0.052\right.$ to 0.590 ; heterogeneity: $\mathrm{I}^{2}=95 \%$, $p<0.01)$, and teacher relations $\left(\mathrm{MD}=0.256,95 \% \mathrm{CI}: 0.013\right.$ to 0.500 ; heterogeneity: $\mathrm{I}^{2}=93 \%$, $p<0.01)$.

However, there was no significant difference between the Taekwondo training groups and controls in the school events subfactor $(\mathrm{MD}=0.324,95 \% \mathrm{CI}:-0.150$ to $0.792, p<0.01$; heterogeneity: $\mathrm{I}^{2}=96 \%$ ).

\subsection{Moderator Analysis}

We performed a meta-ANOVA to detect any moderation effects of the categorical variables: study type (cross-sectional or prospective cohort), sex (male proportion), age (elementary, middle, high, or adult), study quality (good, fair, or poor), publication type (thesis or journal article), and meta-regression for the continuous variable (i.e., sample size) on sociality, character, etiquette, and school life adjustment separately.

The meta-ANOVA yielded a significant moderation effect of sex $(p<0.001)$ in sociality, while the moderation effect of age was found to be significant $(p<0.001)$ in character. Furthermore, etiquette showed significant moderation effects of study type $(p=0.026)$, age $(p<0.001)$, publication type $(p=0.022)$, and sample size $(p=0.018)$. In school life adjustment, sex $(p=0.027)$, age $(p=0.003)$, and study quality $(p=0.038)$ emerged as significant moderators.

\subsection{Publication Bias and Sensitivity Analyses}

\subsubsection{Sociality}

In the analysis of publication bias, the $p$-value was found to be 0.001 in both Egger's test and Begg's test. The contour funnel plot showed that 29 studies had a $p$-value of less than 0.05 . Sensitivity analysis for publication bias using the trim-and-fill method revealed the adjusted overall effect size (MD $=0.138,95 \% \mathrm{CI}$ : 0.055 to 0.220$)$, suggesting a significant improvement in sociality in the Taekwondo training group. There was significant heterogeneity among the included studies $\left.\left(\mathrm{I}^{2}=93.9 \%\right), p<0.01\right)$.

\subsubsection{Character}

As for publication bias, the $p$-value was found to be 0.025 and 0.114 in Egger's test and Begg's test, respectively. There were 26 studies with a $p$-value of less than 0.05 . We performed sensitivity analysis for publication bias using the trim-and-fill method, which revealed the adjusted overall effect size $(\mathrm{MD}=0.2659,95 \% \mathrm{CI}: 0.152$ to 0.378$)$, suggesting a significant character improvement in the Taekwondo training group. There was significant heterogeneity among the included studies $\left.\left(\mathrm{I}^{2}=94.8 \%\right) . p<0.01\right)$.

\subsubsection{Etiquette}

In the analysis of publication bias, the $p$-values were 0.628 and 0.549 in Egger's test and Begg's test, respectively. The contour funnel plot showed that 33 studies had a $p$-value of less than 0.05 . Sensitivity analysis for publication bias using the trim-and-fill method revealed the adjusted overall effect size ( $\mathrm{MD}=0.534,95 \% \mathrm{CI}$ : 0.472-0.596), suggesting a significant improvement in etiquette in the Taekwondo training group. There was significant heterogeneity among the included studies $\left.\left(\mathrm{I}^{2}=78.4 \%\right), p<0.01\right)$.

\subsubsection{School Life Adjustment}

For publication bias, the $p$-value was found to be 0.912 and 0.822 in Egger's test and Begg's test, respectively. There were 23 studies with a $p$-value of less than 0.05 . Since there was no additional study, the adjusted overall effect size yielded by a sensitivity analysis was the same as the existing overall effect size. 


\section{Discussion}

This meta-analysis was conducted to examine Taekwondo training's effect on psychosocial variables such as sociality, character, etiquette, and school life adjustment. In this review of 28 studies, including cross-sectional and intervention studies, the results indicated that Taekwondo training had small to medium effects on psychosocial factors. The interpretation of the results, implications, and limitations is discussed separately by the variables.

\subsection{Sociality}

Our analysis revealed that Taekwondo had a positive effect on sociality in the subfactors of cooperation, law-abidance, leadership, responsibility, sociability, and stability, with a small overall effect size ranging between 0.203 and 0.396 . Among the eight studies, seven were master's theses with a cross-sectional design. Only one peer-reviewed study examined the effect of Taekwondo training by employing a 24-week intervention [3]. As demonstrated in Table 1, six of the included studies targeted elementary school students, mostly upper graders, while two targeted high school students. It is interesting to note that all of the cross-sectional studies included in our meta-analysis reported improvement in social characteristics in general, although differences existed among the subfactors of sociality assessed in each individual study. However, an intervention study by Tae-Hee Lim [3] found that the 24-week Taekwondo program did not result in meaningful improvement in sociality compared to controls. Considering that the results from the cross-sectional studies consistently reported a positive correlation between the sociality outcomes and the years of Taekwondo training $[22,23,25]$, future studies should adopt intervention programs for an extended period of time to examine the cause-and-effect relationship between Taekwondo and social development.

A meta-analysis of studies examining Taekwondo's effect on sociality revealed that Taekwondo training in the long term might be effective for an individual's social development. However, due to the relatively small effect size and the study type (i.e., crosssectional) of the literature synthesized in this meta-analysis, caution needs to be taken to avoid overestimating the link between them. Furthermore, Taekwondo's overall effect on sociality subfactors such as activity, autonomy, and capability were not significant.

We found that, although some studies reported significant correlations between the sociality outcomes of Taekwondo training students and their demographic characteristics, such as the parents' education and income level [22,25], none of these studies further assessed the effects of Taekwondo on the linkage between socioeconomic status and social development. As underserved groups are often known to be more sensitive to exercise effects, having greater room for improvement [34], future studies are encouraged to explore whether Taekwondo training's effect on social development differs depending on socioeconomic factors.

\subsection{Character}

The results of this meta-analysis indicated that Taekwondo training had a positive impact on character in the subfactors of sense of community, consideration, emotionality, leadership, propriety, living, self-establishment, and self-esteem, with small to medium overall effect sizes ranging between 0.311 and 0.560 . Among the nine studies, six were cross-sectional and three were intervention studies. Since the synthesized studies included age groups from preschoolers and elementary school students to high school students and female college students, it appears that Taekwondo training's beneficial effect on character development can be applied to practitioners of various ages. In Yoon's study [35], high school students who participated in morning Taekwondo sessions for nine months exhibited greater improvement in character assessment relative to controls. Similarly, in a cross-sectional study by You [34], which compared character elements of female undergraduates who practiced Taekwondo with those who did not, the Taekwondo practitioners were found to have better emotional stability, self-respect, consideration, sense of community, 
and self-establishment. Consistently, an intervention study with preschool children [10] and the remaining six studies with elementary school students reported greater character enhancement in the Taekwondo training group than in the non-training group.

The principle that Taekwondo brings about positive character development in trainees, especially children, is closely related to the solemn and educational atmosphere of Taekwondo academies and training program content that is intentionally planned and delivered by the Sabum-nim (i.e., master instructor) [31]. As part of the training, they usually include elements of character education such as greeting, etiquette, respect, consideration, rules of conduct, etc. For this reason, regular participation in Taekwondo in the long run not only contributes to personal growth but also to relationships with others, as internalization of these lessons can be transferred to daily life in school and at home [10]. A trainee who has earned a black belt after long and difficult training feels a strong sense of achievement, and these juniors are often given the role of instructor assistants during training, helping other trainees with Poomsae or leading Gihap (i.e., a shout of concentration). These experiences enhance the trainees' leadership and consideration of others, as well as fostering self-esteem and self-efficacy [10,29].

One limitation we observed in the process of this research is that the three variables (i.e., sociality, character, and etiquette) are so closely interconnected that the categorization or conceptualization of the variables varied among studies. For example, Lim [13] divided character factors into individual (etiquette and self-confidence) and interpersonal relationships (leadership). In addition, some studies have overlapping subfactors in different variables. For example, Kang [22] included leadership as a subfactor of sociality, whereas Han [29] viewed leadership as a subfactor of character. Although we performed this meta-analysis according to the categorization intended by the original researchers, future studies will need to better control the effects of the variance in research methods and conceptualization.

\subsection{Etiquette}

Our analysis found that Taekwondo training had a positive effect on etiquette in all of the tested subfactors (deportment, greeting, interpersonal etiquette, language, listening, phone etiquette, etiquette in public places, dining etiquette, and visiting etiquette), with a medium overall effect size ranging between 0.50 and 0.60 . Except for the study by Lim [30], which investigated the effect of a six-month Taekwondo intervention on etiquette in elementary school students, the remaining six studies were cross-sectional studies that compared the self-assessed etiquette of existing Taekwondo trainees and non-trainees. The results showed that the Taekwondo training groups had better etiquette than the non-training groups. Furthermore, Taekwondo's positive impact on etiquette was found to be greater as the training experience increased [23,37].

Proper etiquette is an important component in Taekwondo, as reflected in the saying "Taekwondo begins with manners and ends with manners." Taekwondo instructors continuously educate the trainees to be polite, behave properly, and show respect to others, which becomes a habit expressed in the trainee's life at home and at school, and these basic behaviors develop into good manners. Trulson [45] argued that the traditional form of Taekwondo, which emphasizes martial arts philosophy, is effective for positive youth development. Previous studies also support that the traditional Taekwondo as a martial art has greater psychosocial benefit compared to modern Taekwondo as a sport [46,47]. Considering that the purpose of traditional Taekwondo is not about beating the opponent or winning the match, but rather to improve self-control, it is understandable that training programs including education in the mental and philosophical aspects of Taekwondo might be more useful for psychosocial development than the game-oriented style of Taekwondo training. The differential training effects of these two distinct approaches should be explored in depth in future studies. 


\subsection{School Life Adjustment}

Our meta-analysis revealed that Taekwondo had a positive effect on school life adjustment in the subfactors of learning, friendship, rule compliance, and teacher relations, with small overall effect sizes ranging between 0.195 and 0.421 . The seven included studies were all cross-sectional. Six of these studies were of elementary school students, and the other was of high school students. The synthesis of these studies yielded significant differences in school life adjustment depending on Taekwondo participation. Students who took part in Taekwondo training were shown to have higher scores on the measures of school life adjustment compared to non-trainees. These results imply that Taekwondo training taking place in a peer group may facilitate socialization of the student trainees, which ultimately contributes to school life where they spend a great deal of time with peers.

Furthermore, studies have reported that individuals who train in Taekwondo have better self-control compared to non-trainees, with certified trainees demonstrating even better self-control (reference). In the study by Choi [9], children with better self-control in attention, composure, rule compliance, and interpersonal relationships showed better adaptation to school life. These findings suggest that enhanced self-control through Taekwondo training is closely related to school life adjustment.

It appears that trainees have opportunities to learn attitudes and values such as sportsmanship, rule-observance, self-discipline, role sharing, and cooperation during Taekwondo practice, which are highly effective and important skills for adapting to the school community and establishing a satisfactory life at school. However, since the present research only included cross-sectional studies, caution is required in interpreting these results as a direct effect of Taekwondo training. It would be more appropriate to view Taekwondo's effect on school life adjustment as a significant relationship, rather than causality. Thus, future research will need to investigate its effect on school life adjustment using randomized controlled trials, with varying lengths and trainees' socioeconomic characteristics taken into consideration.

\subsection{Limitations}

This meta-analysis has several limitations. First, differences between studies exist in the lengths of Taekwondo training or intervention, which could lead to heterogeneity across the included studies. Second, among the 28 studies included, only four used intervention designs, while the rest were cross-sectional. Therefore, to confirm causality between Taekwondo training and psychosocial benefits, more interventional research should be conducted due to the paucity of current data published on this issue. Third, excluding studies conducted and published in countries other than Korea might have biased our findings. However, as Korea is Taekwondo's place of origin, it is widely distributed and actively studied. In addition, limiting the inclusion criteria to one country reduced the potential influence of cultural and geographical differences.

Furthermore, researchers used self-report questionnaires to assess psychosocial factors of the study participants in the majority of the included studies, asking them to evaluate their own status. Thus, data can easily be affected by the loss or distortion of memory and the truthfulness of the responses. Therefore, future studies would be more convincing if they adopt more objective and direct measures for investigating the psychosocial effects of Taekwondo. Finally, due to the selected studies and the inevitable heterogeneity among them, the pooled results might include the biases of individual studies as well as new sources of bias, which is a common limitation of meta-analysis. Therefore, future metaanalyses on this topic should integrate more prospective cohort studies or RCTs to confirm the findings of this research.

\section{Conclusions}

In summary, this meta-analysis indicates that Taekwondo training has positive effects on psychosocial factors such as sociality, character, etiquette, and school life adjustment. Specifically, Taekwondo trainees exhibited significantly higher self-assessed scores on 
cooperation, law-abidance, leadership, responsibility, sociability, and stability among the subfactors of sociality. In the character subfactor, Taekwondo trainees were found to have a higher sense of community, consideration, emotionality, leadership, propriety, living, self-establishment, and self-esteem. In terms of etiquette, Taekwondo trainees had better qualities in terms of deportment, greeting, interpersonal etiquette, language, listening, phone etiquette, etiquette in public places, dining etiquette, and visiting etiquette. Finally, the improved psychosocial characteristics seem to be associated with better school life adjustment, as evidenced by higher scores on learning, friendship, rule compliance, and teacher relations in Taekwondo training students relative to non-trainees. However, several concerns, including inherent biases in the sample type, outcome measurements, and intervention settings included in this meta-analysis may limit definitive conclusions. Future studies are encouraged to conduct well-designed RCTs and multiple levels of Taekwondo intervention to validate the findings of the current analysis.

Author Contributions: Conceptualization, S.-H.B. and S.-S.N.; methodology, Y.-J.K., S.-H.B., J.-D.L. and S.-S.N.; software, Y.-J.K. and S.-H.B.; validation, Y.-J.K., S.-H.B., J.-B.P. and S.-S.N.; formal analysis, Y.-J.K. and S.-H.B.; investigation, Y.-J.K., S.-H.B., S.-H.C. and J.-B.P.; resources, Y.-J.K., S.-H.B. and J.-D.L.; data creation, Y.-J.K., S.-H.B. and J.-D.L.; writing original draft preparation, Y.-J.K. and S.-H.B.; writing-review and editing, Y.-J.K., S.-H.B., J.-D.L. and S.-S.N.; visualization, Y.-J.K. and S.-H.B.; supervision, S.-H.C., J.-B.P. and S.-S.N.; project administration, S.-S.N. and J.-B.P.; funding acquisition, J.-D.L., S.-H.C., J.-B.P. and S.-S.N. All authors have read and agreed to the published version of the manuscript.

Funding: This research was supported by Taekwondo Research Institute of Kukkiwon.

Institutional Review Board Statement: The study was conducted according to the guidelines of the Declaration of Helsinki and approved by the Ethics Committee of Konkuk University (7001355201804-E-077) (April 2018).

Informed Consent Statement: Not applicable.

Acknowledgments: All authors sincerely thank Kukkiwon President Lee Dongsub for supporting this study.

Conflicts of Interest: The authors declare no conflict of interest.

\section{References}

1. Ahn, J.; Hong, S.; Park, Y. The History and Culture Identity of Taekwondo as a Traditional Korean Martial Art. Int. J. Hist Sport 2009, 26, 1716-1734. [CrossRef]

2. Kwak, J.; Cho, S. Orientation of Taekwondo Education as a Cultivation of Human Nature for 21st Century. Int. J. Martial Arts. 2017, 3, 1-14. [CrossRef]

3. Lim, T. Change of Youth Sociability According to Taekwondo Discipline. Korean J. Sport Sci. 2009, 20, 387-399. [CrossRef]

4. Dziwenka, R.; Johnson, J.A. Philosophical Perspectives of Practice: Traditional Martial Arts Taekwondo vs. Modern Sports Taekwondo. J. Int. Assoc. Taekwondo Res. 2015, 2,1-8.

5. Choi, H. Encyclopedia of Taekwon-Do; International Taekwondo Federation: Toronto, ON, Canada, 1985.

6. Petrovic, K. The Benefits of Taekwondo Training for Undergraduate Students: A Phenomenological Study. Societies 2017, 7, 27. [CrossRef]

7. Park, D.K.; Schein, A. Taekwondo: The Indomitable Martial Art of Korea; Invisible Cities Press: Montpelier, VT, USA, 2006.

8. Lee, J.; Kim, D. Relation between Belief and Actual Practice of Instructor According to Education in Taekwondo Personality. J. Korea Contents Assoc. 2012, 12, 396-407. [CrossRef]

9. Choi, K. The Effect of Children's Self-Control and School Adjustment According to Taekwondo Practice. Korean J. Phys. Educ. 2008, 47, 115-126.

10. Choi, S.; Kim, H. The Effects of a Taekwondo Based Physical Activity Program on Young Children's Self Esteem and Character Development. J. Korean Alliance Martial Arts 2015, 17, 79-95.

11. Kwak, C. The Effects of TaeKwonDo Training on the Sociability Development of Children. Master's Thesis, Kyunghee University, Seoul, Korea, 2006. Available online: http://khu.dcollection.net/public_resource/pdf/200000043183_20210831141004.pdf (accessed on 20 August 2021).

12. Park, J. School Taekwondo Practitioners' Participation Motives Impact on School Life Satisfaction. Master's Thesis, Korea National Sports University, Seoul, Korea, 2011. Available online: http://knsu.dcollection.net/public_resource/pdf/2000004938 11_20210831140752.pdf (accessed on 20 August 2021). 
13. Lim, T. Empirical Verification of the Effect Taekwondo on Characters in Elementary School Students. Taekwondo J. Kukkiwon 2015, 6, 71-95. [CrossRef]

14. Kim, W.; Kwon, M.; Woo, M. The Intervention Study of Taekwondo-Oriented Physical Activity on Emotional Intelligence and Sociality in Preschoolers. Korean J. Phys. Educ. 2012, 51, 709-719.

15. Won, H. Taekwondo Class after School on Saturday's on Children's Sociability and Adaptation to School-Life. Korean J. Sports Sci. 2014, 23, 771-781.

16. Kim, H.; Won, H. A Study on Influence of an Elementary School Student's Taekwondo Training on Self-Regulation and Sociality Development. Kosoma 2018, 12,37-59. Available online: http://suwon.dcollection.net/public_resource/pdf/000001135163_202 10823163333.pdf (accessed on 20 August 2021). [CrossRef]

17. Bae, J.Y.; Roh, H.T. Regular Taekwondo Training Affects Mood State and Sociality but Not Cognitive Function among International Students in South Korea. Healthcare 2021, 9, 820. [CrossRef]

18. Hong, J.S.; Kim, D.H.; Piquero, A.R. Assessing the Links between Punitive Parenting, Peer Deviance, Social Isolation and Bullying Perpetration and Victimization in South Korean Adolescents. Child Abus. Negl. 2017, 73, 63-70. [CrossRef]

19. Cipra, A.; Hall, L.T. COREMatters: A Bullying Intervention Pilot Study. RMLE Online 2019, 42, 1-13. [CrossRef]

20. Moher, D.; Liberati, A.; Tetzlaff, J.; Altman, D.G.; PRISMA Group. Preferred Reporting Items for Systematic Reviews and Meta-Analyses: The PRISMA Statement. PLoS Med. 2009, 6, e1000097. [CrossRef]

21. DerSimonian, R.; Laird, N. Meta-Analysis in Clinical Trials. Control. Clin. Trials 1986, 7, 177-188. [CrossRef]

22. Kang, W. The Effect of Elementary School Students' Taekwondo Practice on Their Sociality and Mental Health. Master's Thesis, Keimyung University, Daegu, Korea, 2010. Available online: https://dcollection.kmu.ac.kr/public_resource/pdf/000000009121 20210822191731.pdf (accessed on 20 August 2021).

23. Kim, B. Effects of Young People's Taekwondo Training on Courtesy and Development of Sociality. Master's Thesis, Sogang University, Seoul, Korea, 2006. Available online: http:/ /library.sogang.ac.kr/search/media/img/SAT000000310443?metsno=00 0000014079\&fileid=M000000014079_FILE000001.pdf (accessed on 20 August 2021).

24. Kim, M. The Relation of Taekwondo Training of an Elementary School Children to Their Sociality and Aggressiveness. Master's Thesis, Keimyung University, Daegu, Korea, 2007. Available online: https://dcollection.kmu.ac.kr/public_resource/pdf/000000 006298_20210822192500.pdf (accessed on 20 August 2021).

25. Nam, S. A Study on the Difference of the Social Competence of Elementary School Students, Which Could Be Variable According to How Much They Have Trained Taekwondo and Whether They Train It or Not. Master's Thesis, Kookmin University, Seoul, Korea, 2005.

26. An, M. A Study of Leadership and Sociality of Student on Taekwondo Training. Master's Thesis, Korea National University of Education, Cheongju, Korea, 1997. Available online: https://dcollection.knue.ac.kr/common/orgView/000000007983.pdf (accessed on 20 August 2021).

27. Yoon, H. A Study on the Effect of Elementary Students Taekwondo Training to Their Social Ability and Interpersonal Relationship. Master's Thesis, Yong In University, Yongin, Korea, 2005.

28. Lee, D. Taekwondo Skills and Aptitude of High School Education Teach Participants about the Social Development Research. Master's Thesis, Pukyong National University, Busan, Korea, 2008. Available online: http://pknu.dcollection.net/public_ resource/pdf/000001955440_20210822192642.pdf (accessed on 20 August 2021).

29. Han, M.; Nam, Y. The Personality of Elementary School Students under the Influence of Taekwondo Practice. Korean J. Elem. Phys. Educ. 2005, 11, 111-122.

30. Hong, I. The Difference Research on the Development of Manner and Personal Development for the Elementary School's Children by Taekwondo Training. Master's Thesis, Kyunghee University, Seoul, Korea, 2010. Available online: http:/ / khu.dcollection.net/ public_resource/pdf/200000052896_20210822194909.pdf (accessed on 20 August 2021).

31. Jung, M. A Study on the Personality Difference of between Taekwon-Do Trainee, Non-Trainee and Practice Condition in Elementary Boys. Master's Thesis, Wonkwang University, Iksan, Korea, 2007. Available online: http:/ / wonkwang.dcollection. net/public_resource/pdf/000001988530_20210822195203.pdf (accessed on 20 August 2021).

32. Lee, H. The Impacts of Taekwondo Training on the Personality of School Children. Master's Thesis, Yongin University, Yongin, Korea, 2005.

33. Lim, J.G. Study on Elementary School Students' Improvement of Character through TaeKwonDo Training. J. Sport Leis. Stud. 2008, 34, 549-558. [CrossRef]

34. You, H. The Differences in Manners and Personalities between Participating Female College and Non-Participating Female College Students Taekwondo. Master's Thesis, Inha University, Incheon, Korea, 2012. Available online: http:/ / inha.dcollection. net/public_resource/pdf/200000243593_20210822200532.pdf (accessed on 20 August 2021).

35. Yoon, J. The Effects of Participating in an Early Morning Taekwondo Program on Personalities and Attitudes toward Academics of High School Students in a Boarding School. Master's Thesis, Korean National Sport University, Seoul, Korea, 2019. Available online: http:/ / knsu.dcollection.net/public_resource/pdf/200000492494_20210822200733.pdf (accessed on 20 August 2021).

36. Lee, Y. Effects of Primary Student's on Taekwondo Practice Etiquette and Self-Control. Korea Sport Res. 2003, 14, 981-992.

37. Yang, K. The Influence of Elementary School Students' on TaeKwonDo Practice, Etiquette Awareness and Etiquette Behavior. Master's Thesis, Kyunghee University, Seoul, Korea, 2006. Available online: http://khu.dcollection.net/public_resource/pdf/20 0000043194_20210822201007.pdf (accessed on 20 August 2021). 
38. Tae-Hee Lim, T. Change of Youth Courtesy According to Taekwondo Discipline. Taekwondo J. Kukkiwon 2017, 8, 231-248. [CrossRef]

39. Kim, Y. The Effect of Children's Peer Relationship and School Adjustment during Taekwondo Practice. Master's Thesis, Woosuk University, Wanju, Korea, 2007. Available online: http:/ / khu.dcollection.net/public_resource/pdf/200000051273_2021082316255 3.pdf (accessed on 20 August 2021).

40. Kim, H. Relationship between Taekwondo Practice of Teenagers and School Life Adaptation and Satisfaction. Master's Thesis, The University of Suwon, Hwaseong, Korea, 2011.

41. Kim, J.; Moon, H. The Effect of after-School Taekwondo Training on Peer Relationship and School Adjustment of Elementary School Student. J. Korean Soc. Wellness 2015, 10, 61-72.

42. Kim, S. The Effect of Character Development through Takwondo Training Experience on School Life Adjustment among Middle School Students. Master's Thesis, Kyunghee University, Daegu, Korea, 2016. Available online: http:/ / woosuk.dcollection.net/ public_resource/pdf/000002306283_20210823162328.pdf (accessed on 20 August 2021).

43. Yoo, B. The Relationship between Physical Self-Concept and School Life Adjustment in Elementary School Taekwondo Participants. Master's Thesis, Konkuk University, Seoul, Korea, 2013. Available online: http://konkuk.dcollection.net/public_resource/pdf/ 000001540912_20210823163454.pdf (accessed on 20 August 2021).

44. Yoon, S.; Hong, M. The Effect of Elemenatry School Student's Taekwondo Practice on School Adjustment. Yongin Univ. J. Martial Arts Inst. 2005, 16, 197-209.

45. Trulson, M.E. Martial Arts Training: A Novel “Cure” for Juvenile Delinquency. Hum. Relat. 1986, 39, 1131-1140. [CrossRef]

46. Focht, B.C.; Bouchard, L.J.; Murphey, M. Influence of Martial Arts Training on the Perception of Experimentally Induced Pressure Pain and Selected Psychological Responses. J. Sport Behav. 2000, 23, 232-244.

47. Lakes, K.D.; Hoyt, W.T. Promoting Self-Regulation through School-Based Martial Arts Training. J. Appl. Dev. Psychol. 2004, 25, 283-302. [CrossRef] 